\title{
NUMERICAL STUDY OF TURBULENT HEAT TRANSFER IN A HORIZONTAL CHANNEL PROVIDED WITH SQUARE BLOCKS: EFFECT OF THE INTER BLOCKS SPACING
}

\author{
Kamal Amghar ${ }^{1^{*}}$, Abdelkader Filali ${ }^{2}$, Mohamed Ali Louhibi ${ }^{1}$, Hicham Bouali ${ }^{3}$, Najim Salhi ${ }^{1}$ and Merzouki \\ Salhi ${ }^{1}$
}

\begin{abstract}
In the present paper, numerical simulation is carried out to investigate turbulent flow structure and heat transfer analysis in a two-dimensional horizontal plane channel, contains square blocks arranged in tandem or side by side arrangement. The k- $\varepsilon$ model is used to describe turbulence phenomena, and governing equations are solved by a finite volume method, with SIMPLEC algorithm is applied for the coupling of the velocity-pressure variables. The power-law scheme is used for the discretization of the convective terms in the momentum equations. Presented results illustrates the effect of the transverse $\left(\mathrm{G}_{\mathrm{T}}\right)$ and longitudinal $\left(\mathrm{G}_{\mathrm{L}}\right)$ spacing between the blocks on flow structure and heat transfer for a wide range of Reynolds number $\left(10^{4} \leq \mathrm{Re} \leq 5 \times 10^{4}\right)$. Numerical results show a very good agreement in comparison with available data in the literature.
\end{abstract}

Keywords: Turbulent Flow, Heat Transfer, Numerical Solution, Square Blocks, Blocks Spacing, Channel, Finite Volume Method

\section{INTRODUCTION}

Recently, heat transfer enhancement by forced convection at high Reynolds numbers was considered as a most important subject for the scientific community. The heat transfer problem is important because of its many industrial applications, like cooling of electronic systems, aeronautics and compact heat exchangers [1-4]. Literature survey shows that most of the existing studies of turbulent flow in horizontal channel with an internal arrangement of rectangular blocks are related to forced or mixed convection phenomenon [5-8] for the objective of improving the heat transfer rate and the understanding of the fundamental flow interactions mechanisms occurring in various industrial technologies. However, many investigations focused on the modeling and optimization of mounted bars and fins along the channel walls to determine the optimum fin height, aspect ratio and spacing between the blocks to obtain a maximum thermal dissipation. For example, Nakagawa et al. [9] Carried out experimentally the analysis of heat transfer in a channel flow with a rectangular cylinder having various aspect ratio, $\mathrm{b} / \mathrm{h}=0.5,1,2$, and 3 . Nusselt number and fluctuations of the wall heat flux were measured with thin film-heat flux sensors. Measurements showed that the heat transfer increases extensively with an insertion of the rectangular cylinder at the downstream region of the cylinder who's the wall heat flux creates the shedding vortices from downstream in the bars. Do-Hyeong Kim et al. [10] investigated numerically the turbulent flow over a square cylinder in a channel using Large Eddy Simulation (LES) model. The investigation is carried out to compare the (LES) results with the experimental data of Nakagawa et al. [9] Excellent agreements between both results were obtained. Numerical study for forced convection heat transfer of the transient flow over isothermal square cylinders inside a horizontal channel was performed by Parthasarathy et al. [11]. The spacing between the square blocks and the square aspect ratio were fixed along the computational problem. They have reported that the appearance of rotating vortices starts when $R e=48$ and that the temperature at the interfaces of the blocks decreases as the Reynolds number increases. Valencia et al. [12] analyzed numerically the heat transfer for a transient turbulent flow in a channel having periodically mounted square bars arranged side by side. The $k-\varepsilon$ model and the SIMPLEC algorithm were used for the turbulence modeling and the pressure-velocity coupling, respectively.

This paper was recommended for publication in revised form by Regional Editor N. Filiz Ozdil

${ }^{1 *}$ Laboratory of Mechanics and Energy, Mohammed $1^{\text {st }}$ University, Oujda, Morocco

${ }^{2}$ ENPC, National Polytechnic University of Constantine, Constantine, Algeria

${ }^{3}$ Laboratory of Renewable Energy, Embedded System and Information Processing, National school of Applied Science, Morocco

*E-mail address: amgharkamaler@gmail.com

Orcid id: 0000-0002-2509-8433, 0000-0002-5794-565X

Manuscript Received 06 March 2019, Accepted 02 September 2019 
Difference transverse separation distances between the bars were considered for a constant Reynolds number of $2 \times 10^{4}$. Results showed that presence of periodically square bars induces complex periodic vortex shedding and that transient flow behavior, heat transfer and pressure drop strongly dependent on the transverse separation distance of the bars. Same authors [13] studied numerically the heat transfer enhancement the presence of square cylinder within a channel duct. Results indicated that the heat transfer and flow pattern become more effective as the aspect ratio and Reynolds number increases. Similar, Franke and Rodi [14] calculated numerically the flow passing a square bar at $R e=2 \times 10^{4}$ using Reynolds stress equation and $k-\varepsilon$ models. They found that Reynolds stress model provides better results, but it tends to over predict the periodic fluctuating motion. However, both models were unable missing some other details of the flow behavior. Perng and $\mathrm{Wu}$ [5] conducted numerical study on heat transfer enhancement for turbulent mixed convection flow in horizontal block-heated channel. The Large Eddy Simulation (LES) was used and SIMPLEC algorithm was considered for the velocity-pressure coupling. A rectangular turbulator was placed in the channel to improve the heat transfer rate. Reynolds number was kept constant at $R e=5000$ and three rectangular turbulator width-to-height aspect ratios were considered ( $\mathrm{AR}=0.25,0.5$ and 1.0) with for various Grashof numbers of $G_{r}(0$ $\left.5 \times 10^{8}\right)$. They reported that the heat transfer performance may effectively enhanced when the rectangular turbulator are mounted above an upstream block. Kumar al. [15] investigated numerically the effect of blockage ratio of inclined square bars on flow structure and heat transfer of non-Newtonian fluid flow in horizontal channel. Results indicated that the increase of the blockage ratio increased the drag coefficient and the average Nusselt number. The maximum enhancement in heat transfer was about 49, 41 and 35\% respectively for blocking values 50, 25 and 12.5\%, respectively, compared to the Newtonian limit. In addition, the average heat transfer for the inclined square cylinder $\left(\alpha=45^{\circ}\right)$ was always higher compared to the regular case of $\left(\alpha=0^{\circ}\right)$. Bouchenafa et al. [16] carried out numerical study of the turbulent forced convection problem in channel duct having internal heat sink composed by several square bars. Simple blocks and blocks divided were considered. The effect of longitudinal and transversal spaces between the bars on the heat transfer and flow fields distribution was studied. Barman et al. [17] used ANSYS FLUENT solver to study the two-dimensional turbulent forced convection along a rectangular channel having cylindrical obstacles located near the traces. Results presented the effect of different position ratios of the obstacles and Reynolds number, on the heat transfer and hydrodynamic of the flow. It is reported that when both obstacles are placed vertically with same position ratio, the rate of heat transfer increases when the obstacle position ratio is increased. Recently, numerical investigation is carried out by Zhang et al. [18] on forced convection problem in a channel with two tandem cylinders having rounded corners with a radius of curvature $\mathrm{R}$ and for $R e=100$. The two cylinders are separated by transverse spacing GR. Results indicated that the two parameters; spacing GR and radius of curvature have significantly affected the local heat transfer and structure of flow. Same authors [19] examined the effect of the aspect ratio (AR) and gap ratio (GR) for similar problem with two tandem rectangular cylinders in a channel at $R e=100$. Two flow regimes could be characterized based on the values of (GR); a steady flow regime at GR $\leq 3$ and the unsteady flow regime at $\mathrm{GR} \geq 4$. The changes in the aspect ratio (AR) and gap ratio (GR) affected considerably the heat transfer rate. On the other hand, many numerical studies have been carried out to characterize the heat transfer enhancement using nanofluids in such geometries such as the work by Sheikholeslami et al. [20] who investigated numerically the flow structure and heat transfer performance of nanofluid in a tube with double twisted tapes. Simulation have been examined with varying the height of turbulateur (b) for various values $\mathrm{b}=5 ; 10$ and $15 \mathrm{~mm}$ and Reynolds number (Re $=50000 ; 10000 ; 15000)$. They have examined the velocity, generation of entropy and temperature according to cases of parameters $\mathrm{b}$ and Reynolds number. Indeed, these authors shows that the least entropy generation has been increased for the case of $R e=15000$ and $\mathrm{b}=15 \mathrm{~mm}$. In addition, same authors [21] studied numerically forced convection in a combined turbulateur that have been suggested to realize good thermal performance. The $\mathrm{CuO}$ nanofluid fluid was considered with the homogeneous model. The effect of Reynolds number and height of turbulator (b) on the velocity profile, exergy loss, pressure and temperature have been investigated. their results shown that an augmentation of the parameter $\mathrm{b}$ increases the heat transfer and the velocity in a turbulator, however, the exergy loss decreases with augmentation of pumping power. Further analysis by Scheikholeslam et al. [22] have been carried for the design of thermal storage unit using 3D simulation of nanofluid with the presence of $\mathrm{V}$ shaped fins. The effect of nanofluid concentration and the angle of $\mathrm{V}$ shaped fins on the efficiency of energy storage have been considered. Results showed that increasing the angle of the $\mathrm{V}$ shaped fins increases the discharging rate. However, increasing the length of fin 
decreases the discharging rate. Furthermore, the use of copper oxide helps solidification process. In addition, earlier work have been studied by Bouchenafa et al.[29]. They authors studied the effect of nanoparticles on the heat transfer and structure of fluid. The results show that the heat transfer has important in comparison with pure fluid, and the increasing of $\mathrm{A} 12 \mathrm{O} 3$ concentration increase the thermal and dynamic parameters as the friction coefficient.

The main contribution of the present study is the investigation of the forced convection problem in channel duct having four square blocks installed in tandem and side by side arrangement and their effects on the flow patterns and heat transfer characteristics. Most of the previously studies focused only on two squares or different shaped blocks. A parametric study is conducted, and a set of graphical results is presented and discussed and may enhance the understanding on the heat transfer mechanisms with the variation of the spacing between the four blocks. Presented results illustrates the effect of the transverse $\left(\mathrm{G}_{\mathrm{T}}\right)$ and longitudinal $\left(\mathrm{G}_{\mathrm{L}}\right)$ spacing between the blocks on flow structure and heat transfer for a wide range of Reynolds number $\left(10^{4} \leq \mathrm{Re} \leq 5 \times 10^{4}\right)$. Results are discussed in terms of the velocity and turbulent kinetic energy field and also the variation of the local and average Nusselt number and skin friction coefficient.

\section{MATHEMATICAL FORMULATION Problem Statement}

Two-dimensional governing equations have been used to study the structure flow and heat transfer in a horizontal partitioned channel. The relevant geometric parameters and coordinates are defined in Figure 1 . The flow is assumed incompressible, turbulent and two-dimensional in horizontal channel of height $H$ containing different uniformly spaced square blocks of side-length $d$ mounted along the axis channel. The blocks are adiabatic surfaces and the upper and lower walls of the channel are maintained at constant temperature $T_{w}$. Physical properties of the working fluid (air) are assumed constant at the inlet temperature $T_{0}$, except the density which varies with the temperature in the buoyancy term and it is evaluated using the Boussinesq approximation. Based on the above-mentioned assumptions, governing equations can be summarized as follows:

(a)
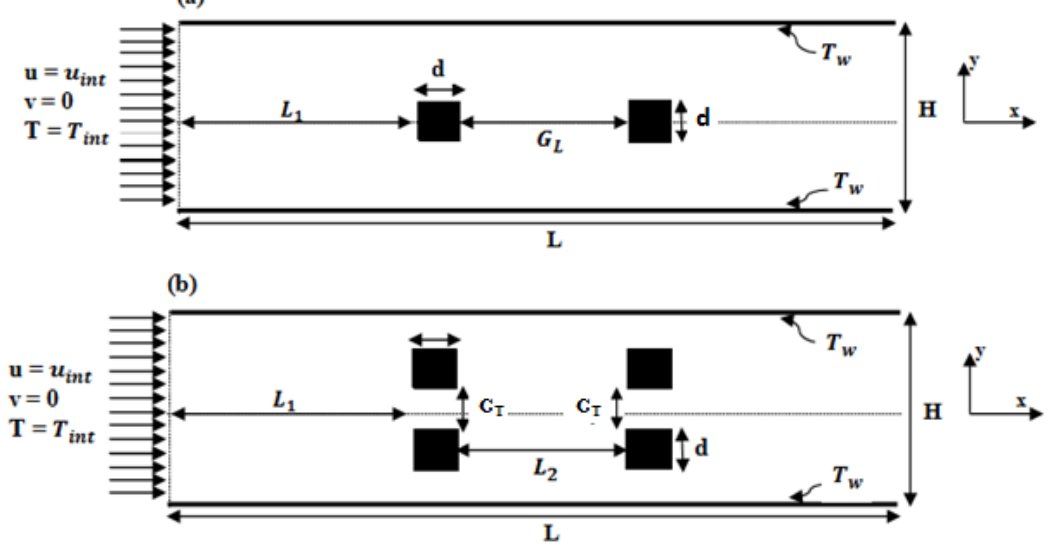

Figure 1. Geometrical models, a) two square bars in tandem arrangement, b) four square bars in side by side arrangement

Continuity equation:

$$
\frac{\partial(\rho u)}{\partial x}+\frac{\partial(\rho v)}{\partial y}=0
$$

Momentum equation in $\mathrm{x}$-direction:

$$
\frac{\partial\left(\rho u^{2}\right)}{\partial x}+\frac{\partial(\rho u v)}{\partial y}=-\frac{\partial P}{\partial x}+\frac{\partial}{\partial x}\left[\left(\mu_{l}+\mu_{t}\right)\left(\frac{\partial u}{\partial x}\right)\right]+\frac{\partial}{\partial y}\left[\left(\mu_{l}+\mu_{t}\right)\left(\frac{\partial u}{\partial y}\right)\right]
$$

Momentum equation in y-direction: 


$$
\frac{\partial(\rho u v)}{\partial x}+\frac{\partial\left(\rho v^{2}\right)}{\partial y}=-\frac{\partial P}{\partial y}+\frac{\partial}{\partial x}\left[\left(\mu_{l}+\mu_{t}\right)\left(\frac{\partial v}{\partial x}\right)\right]+\frac{\partial}{\partial y}\left[\left(\mu_{l}+\mu_{t}\right)\left(\frac{\partial v}{\partial y}\right)\right]
$$

Energy equation:

$$
\frac{\partial(\rho u T)}{\partial x}+\frac{\partial(\rho v T)}{\partial y}=\frac{\partial}{\partial x}\left[\left(\mu_{l}+\frac{\mu_{t}}{\sigma_{T}}\right)\left(\frac{\partial T}{\partial x}\right)\right]+\frac{\partial}{\partial y}\left[\left(\mu_{l}+\frac{\mu_{t}}{\sigma_{T}}\right)\left(\frac{\partial T}{\partial y}\right)\right]
$$

The $k-\varepsilon$ model is chosen for the present study and the transport equations for $k$ and $\varepsilon$ can be written as follows, Launder and Spalding [23]:

Turbulent energy equation:

$$
\frac{\partial(\rho u k)}{\partial x}+\frac{\partial(\rho v k)}{\partial y}=\frac{\partial}{\partial x}\left[\left(\mu_{l}+\frac{\mu_{t}}{\sigma_{k}}\right)\left(\frac{\partial k}{\partial x}\right)\right]+\frac{\partial}{\partial y}\left[\left(\mu_{l}+\frac{\mu_{t}}{\sigma_{k}}\right)\left(\frac{\partial k}{\partial y}\right)\right]
$$

Turbulent dissipation equation:

$$
\frac{\partial(\rho u \varepsilon)}{\partial x}+\frac{\partial(\rho v \varepsilon)}{\partial y}=\frac{\partial}{\partial x}\left[\left(\mu_{l}+\frac{\mu_{t}}{\sigma_{\varepsilon}}\right)\left(\frac{\partial \varepsilon}{\partial x}\right)\right]+\frac{\partial}{\partial y}\left[\left(\mu_{l}+\frac{\mu_{t}}{\sigma_{\varepsilon}}\right)\left(\frac{\partial \varepsilon}{\partial y}\right)\right]
$$

while the turbulent viscosity is given by:

$$
\mu_{t}=\rho c_{\mu} \frac{k^{2}}{\varepsilon}
$$

For the $k-\varepsilon$ model, the constant terms take the values: $C_{\mu}=0.09, C_{l}=1.44, C_{2}=1.92, \sigma_{k}=1.0, \sigma_{\varepsilon}=1.3$

\section{Boundary Conditions}

The boundary conditions applied to the current flow and heat transfer problem are defined as:

At inlet:

$$
\mathrm{x}=0 \text { and } 0 \leq y \leq H \quad u=u_{\text {int }}=0.71 \mathrm{~m} / \mathrm{s}, \mathrm{v}=0, T=T_{\text {int }}=298 \mathrm{~K}
$$

At outlet:

$$
\mathrm{x}=\mathrm{L} \text { and } 0 \leq y \leq H \quad \frac{\partial \phi}{\partial x}=0 \text { with } \phi=u, v, T, k, \varepsilon
$$

At the upper wall:

$$
\mathrm{y}=0 \text { and } 0 \leq x \leq L \quad u=v=0, T=T_{w}=596 K
$$

At the lower wall:

$$
\mathrm{y}=\mathrm{H} \text { and } 0 \leq x \leq L \quad u=v=0, T=T_{w}=596 K
$$

At the blocks:

$$
u=v=0 \text { and the blocks are adiabatic }
$$

\section{NUMERICAL METHOD}

In the present study, numerical investigation has been performed to analyze turbulent fluid flow behavior along with forced convective heat transfer in a two-dimensional horizontal plane channel. The channel contains square 
blocks arranged in tandem or side by side arrangement. The standard $k-\varepsilon$ has been selected for the modeling of turbulence and governing equations are solved using the commercial code ANSYS FLUENT.

Governing Equations, (1) - (6), controlling the fluid flow and heat transfer were solved numerically using a finite volume method. The stability of the solution, the convection and diffusion terms in the Navier-Stokes equations are approximated respectively by the third order upwind scheme [24] and the second order central difference scheme, also second order scheme is used for the pressure. SIMPLE algorithm [24] is used for the treatment of the pressurevelocity coupling and the flowchart of the algorithm is illustrated in Figure 2.

To obtain grid independent results, a series of grid tests were performed. The convergence of the iterative algorithm is continued until the residual values for velocity and remaining variables were less than $10^{-5}$.

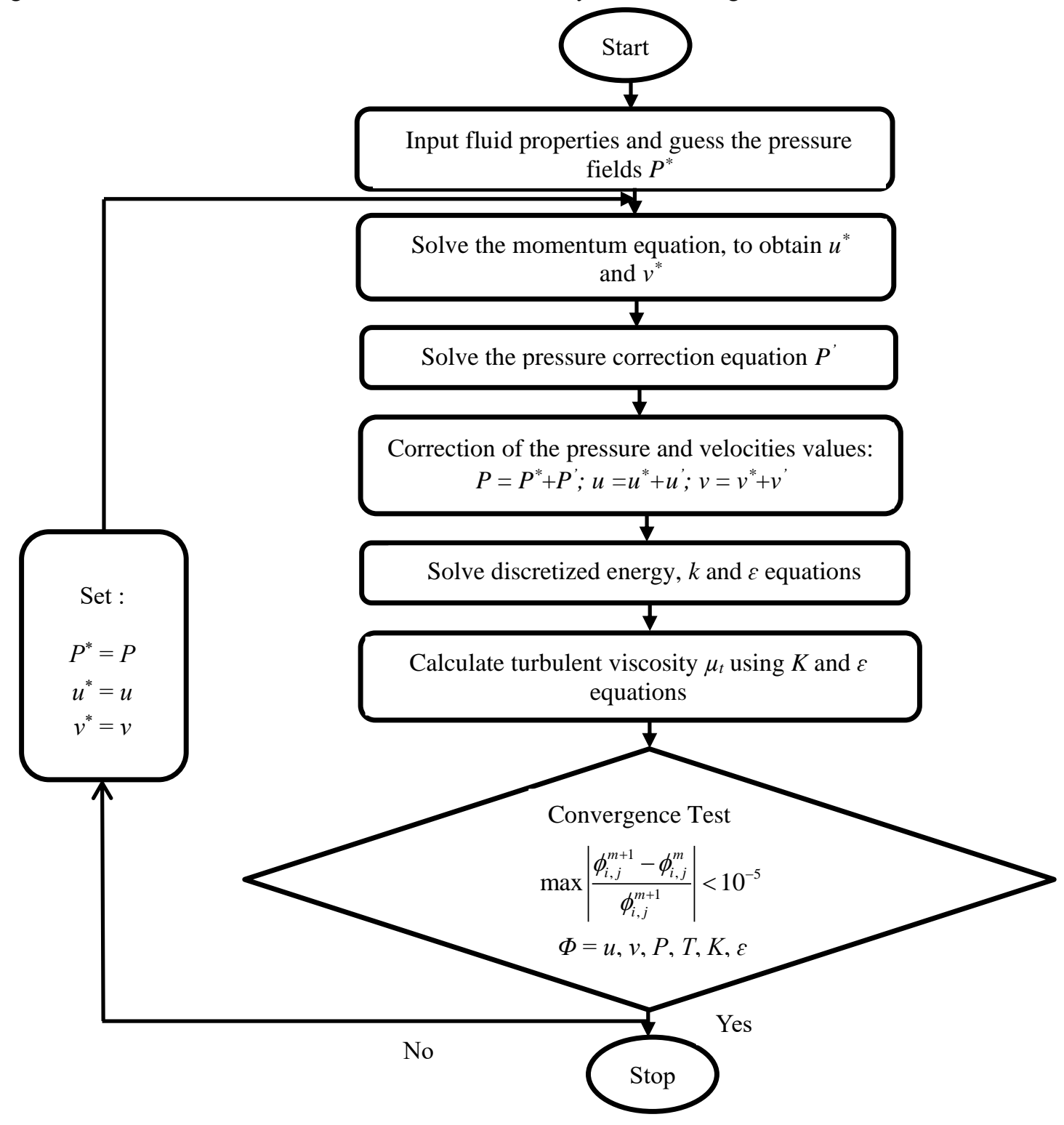

Figure 2. Flowchart of the numerical algorithm

Four parameters of interest in the present work namely: Reynolds number, local and average Nusselt number, skin friction coefficient and coefficient of friction factor could be defined as:

The Reynolds number is given by: 


$$
R_{e}=\frac{u_{0} \times H}{v}
$$

The local Nusselt number $N u$ is defined by:

$$
N u=\frac{h_{x} \times H}{\lambda_{f}}=\frac{Q \times H}{\lambda_{f}\left(T_{w}-T_{b}\right)}
$$

Where $\mathrm{Q}$ is the imposed wall heat flux, $\mathrm{H}$ is the Channel height, $\mathrm{T}_{\mathrm{w}}$ is the wall temperature, $\mathrm{T}_{\mathrm{b}}$ is the fluid bulk temperature and $\lambda_{f}$ is the fluid thermal conductivity.

The average Nusselt number $N_{u m}$ is calculated by the following expression:

$$
N_{u m}=\frac{1}{L} \int N u d x
$$

The skin friction coefficient $C_{f}$ can be obtained by [25]:

$$
C_{f}=\frac{\tau_{w}}{\frac{1}{2} \times \rho \times u_{0}^{2}}
$$

The coefficient of friction factor is computed using Darcy Weisbach formula [26-27]:

$$
f=\Delta p \times \frac{d}{L} \times \frac{2}{\rho u_{0}^{2}}
$$

\section{Grid Independence Study and Code Validation}

A non-uniform grid of quadrilateral cells types is considered, and mesh are refined near the channel walls and the square blocks as shown in Figure 3. Grid independent tests are performed for the validity and the accuracy of calculations. This choice is supported by the results of the grid refinement study as presented in Table 1 and carried out for the case of four internal square blocks at $R_{e}=10^{4}$. Table 1 presents a comparison of the local Nusselt number $N u$, skin friction factor $C_{f}$ and drag coefficient $C_{D}$ for the different tested grids.

The analysis of the results shows that the maximum difference between the results of $340 \times 100$ cells and $360 \times 120$ is less than $2.5 \%$ which is almost similar to the cases of highest number of cells. Therefore, the grid with $340 \times 100$ cells is used in the present study to minimize the computation costs with very good accuracy. It is to mention that when varying the spacing between the blocks $G_{L}$, different mesh frequency was adopted to maintain an accurate solution of the hydrodynamic and thermal boundary layers near the wall surfaces. The decrease in the number of cells between the blocks for the changes from $G_{L} / d=10$ to $8.875,7.75,6.665$ and 5.5 , are $11,22,33$ and $55 \%$, respectively and the decrease in the number of cells between the blocks for the changes from $\mathrm{G}_{\mathrm{T}}=0.087$ to 0.058 and 0.029 , are 65 and $33 \%$, respectively. In all these cases, the total number of cells is kept constant and correspond to the case of independent solution with $340 \times 100$ cells. This means that reducing the number of cells between the blocks correspond to an increase in the cells surrounding the blocks and vice-versa.

The thermal model as described in the present work has been tested by comparing our simulation results with the published results of Alvarez et al. [28], for the forced convection problem in horizontal channel. The comparison of the present numerical results for the ratio of the local to the mean Nusselt number without block $N u / N u_{0}$ and the ratio of the apparent friction coefficient $f l f_{0}$ with those obtained by Alvarez et al. [28] for the case of longitudinal spacing $\mathrm{G}_{\mathrm{L}}$ and the case of transverse spacing $\mathrm{G}_{\mathrm{T}}$ are presented in figures 4 and 5 , respectively. A good agreement between the two result sets is obtained with an estimated difference less than $1 \%$. 


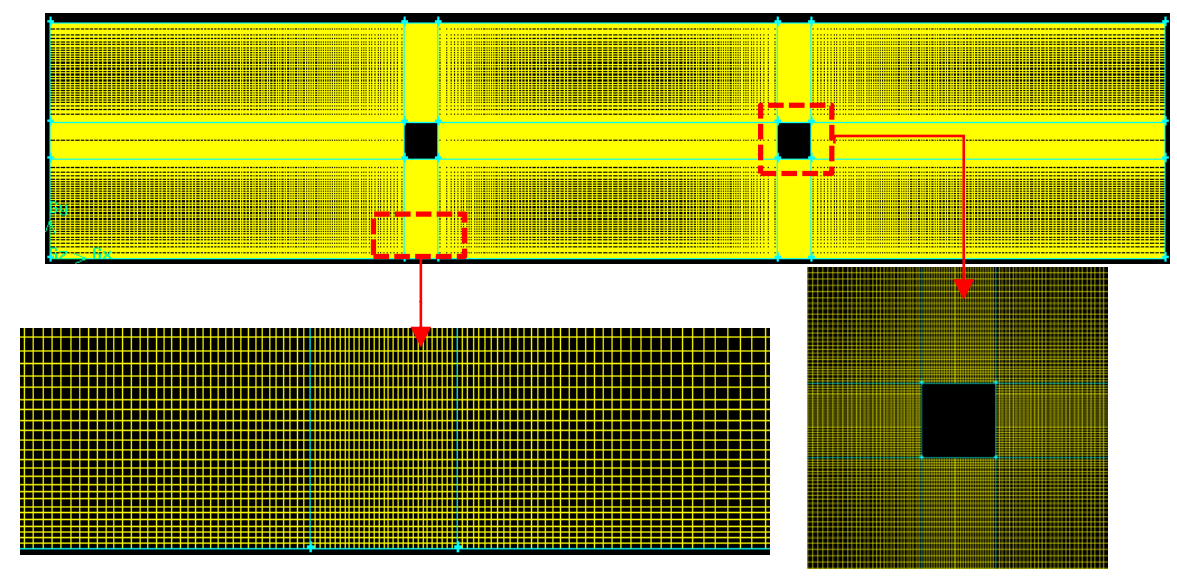

a) Meshing of the first geometry with two square blocks

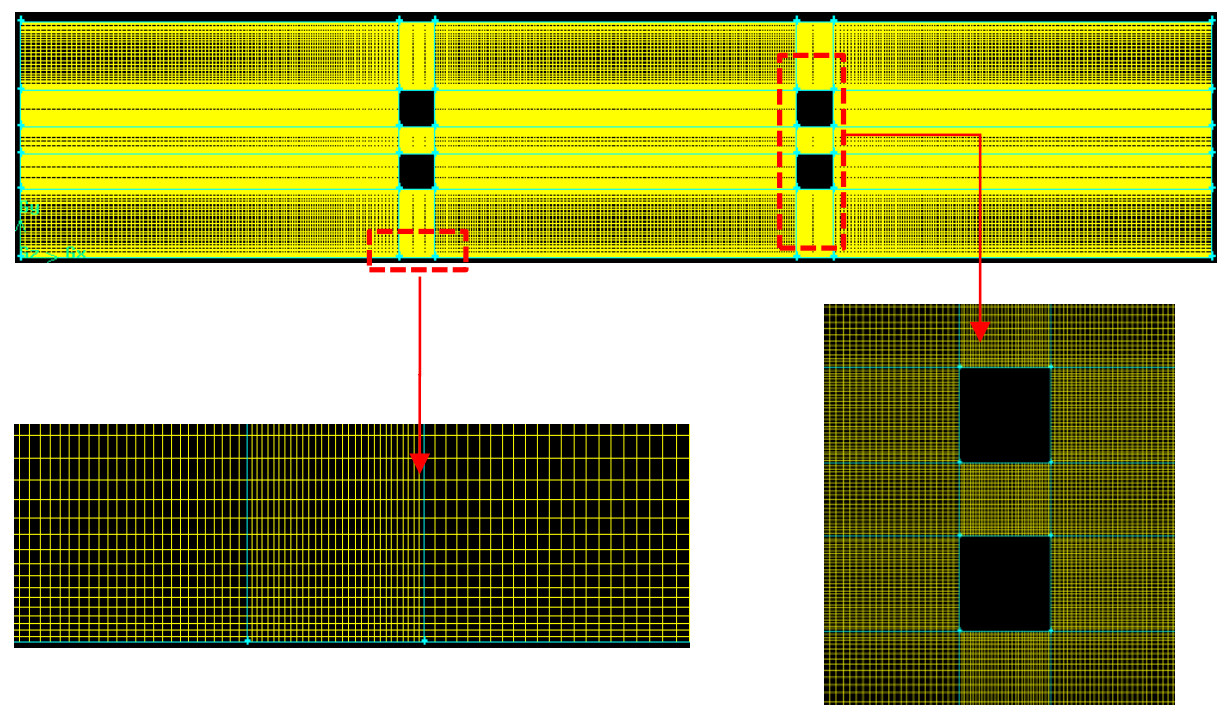

b) Meshing of the second geometry with four square blocks

Figure 3. Grid points distribution for $340 \times 100$ mesh two geometries a) first, b) two

Table 1. Comparison of results for different mesh grids

\begin{tabular}{|c|l|l|l|l|l|l|}
\hline $\begin{array}{c}\text { Grid }(\mathrm{X} \text { and } \\
\text { Y Directions) }\end{array}$ & $300 \times 60$ & $320 \times 80$ & $340 \times 100$ & $360 \times 120$ & $380 \times 140$ & $400 \times 160$ \\
\hline$N u$ & 64.7801 & 64.8492 & 65.9080 & 65.9114 & 65.9202 & 65.9300 \\
\hline$C_{f}$ & 16.01 & 16.23 & 17.10 & 17.15 & 17.56 & 17.98 \\
\hline$C_{D}$ & 0.1800 & 0.1818 & 0.1860 & 0.1867 & 0.1869 & 0.1895 \\
\hline
\end{tabular}



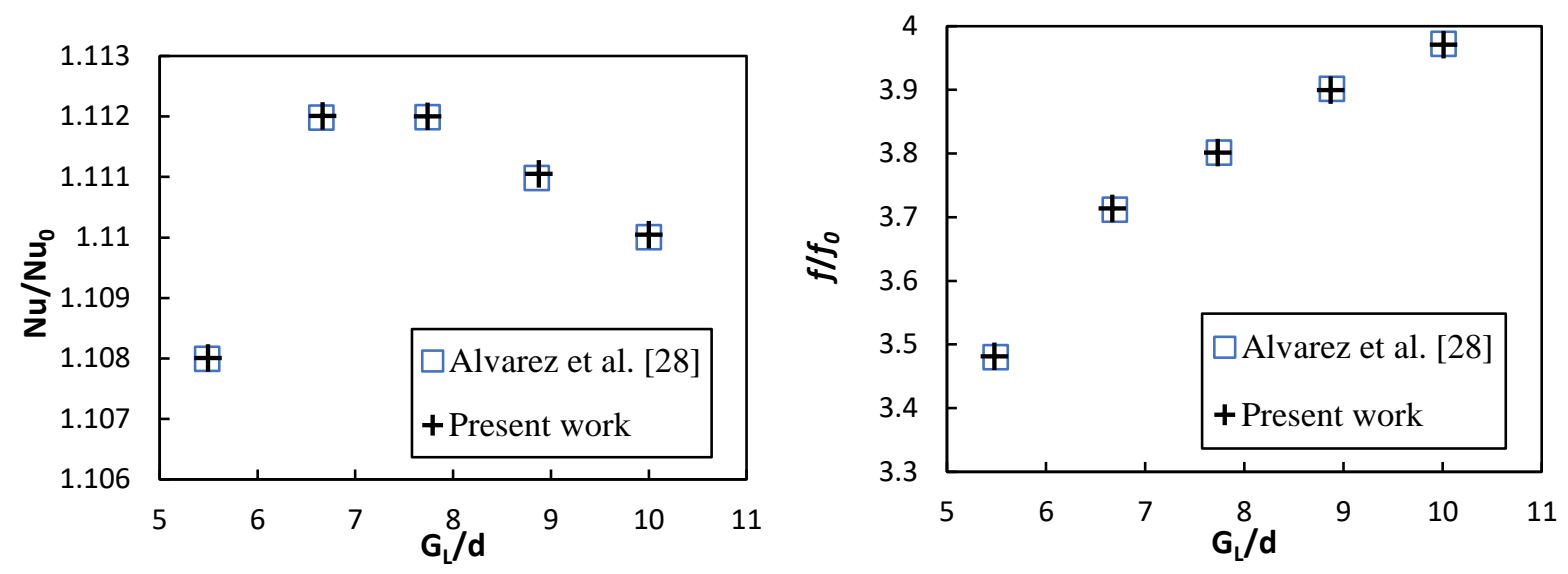

Figure 4. Comparison of the present numerical results of the normalized Nusselt number $\mathrm{Nu} / \mathrm{Nu} 0$ and the normalized friction factor $f / f_{0}$ with the results of Alvarez et al. [28]. Case of longitudinal spacing $\mathrm{G}_{\mathrm{L}}$
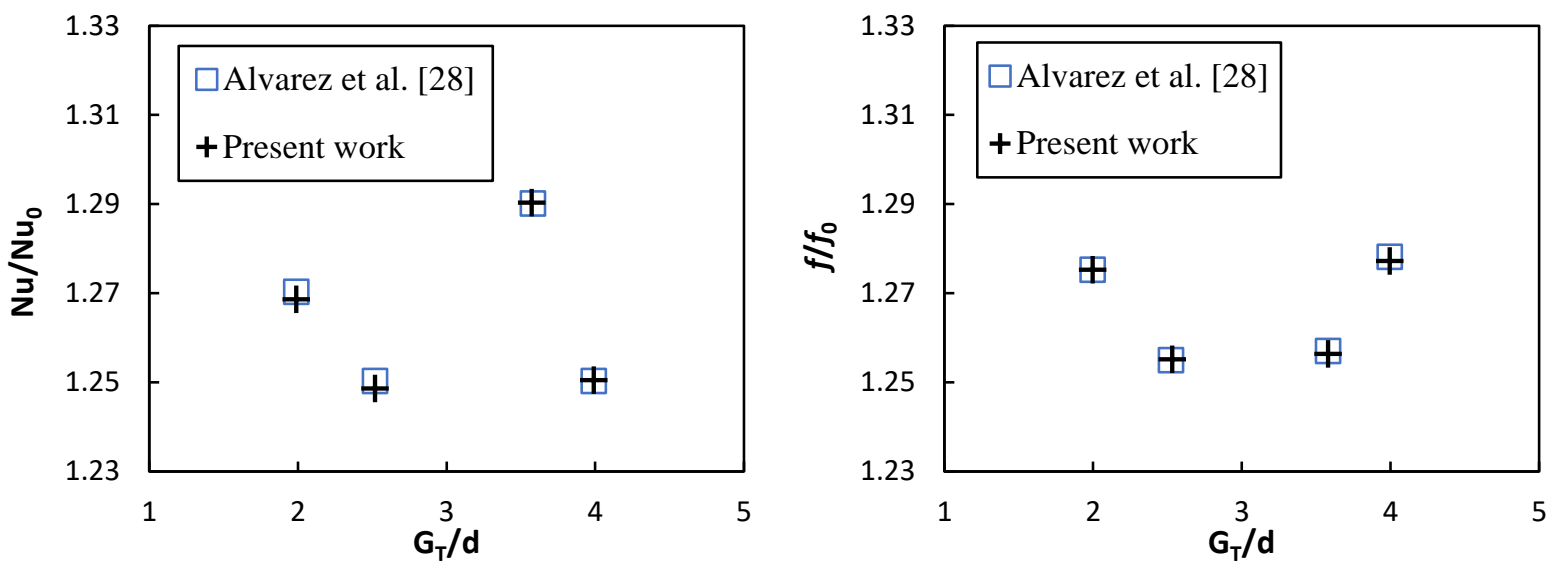

Figure 5. Comparison of the present numerical results of the normalized Nusselt number $\mathrm{Nu} / \mathrm{Nu} 0$ and the normalized friction factor $f / f_{0}$ with the results of Alvarez et al. [28]. Case of transverse spacing $\mathrm{G}_{\mathrm{T}}$

\section{RESULTS AND DISCUSSION}

In this section, the effects of the geometrical parameters such as the spacing between the blocks $G_{L}$ and $G_{T}$ are presented and discussed in detail for the case of turbulent forced convection problem. Prandtl number is assumed to be constant at $P_{r}=0.71$. The inlet temperature $T_{0}$ is set equal to $298 \mathrm{~K}$ and the temperature of the horizontals walls is $2 \times T_{0}$. Results are illustrated by the respective profiles of velocity, turbulent kinetic energy, Nusselt number and the skin friction factor (local and average plots).

\section{Velocity and Turbulent Kinetic Energy}

Figure 6 shows the contour plots of the velocity magnitude for Reynolds number $R e=10^{4}$ and $d / H=0.152$ and for different values of the spacing between the blocks $G_{L} / d=5.5,6.665,7.75,8.875$ and 10 . Case 1 and case 2 represents the cases for the channel flow with two and four-square blocks with $G_{T}=0.029 \mathrm{~m}$, respectively. First, a result shows a perfect symmetric distribution (relative to channel centerline) of the velocity contours. It is observed also that the size of recirculation zones behind the first block and those located between the internal blocks and the channel walls are affected by the variation of the space between the blocks $G_{L} / d$. 


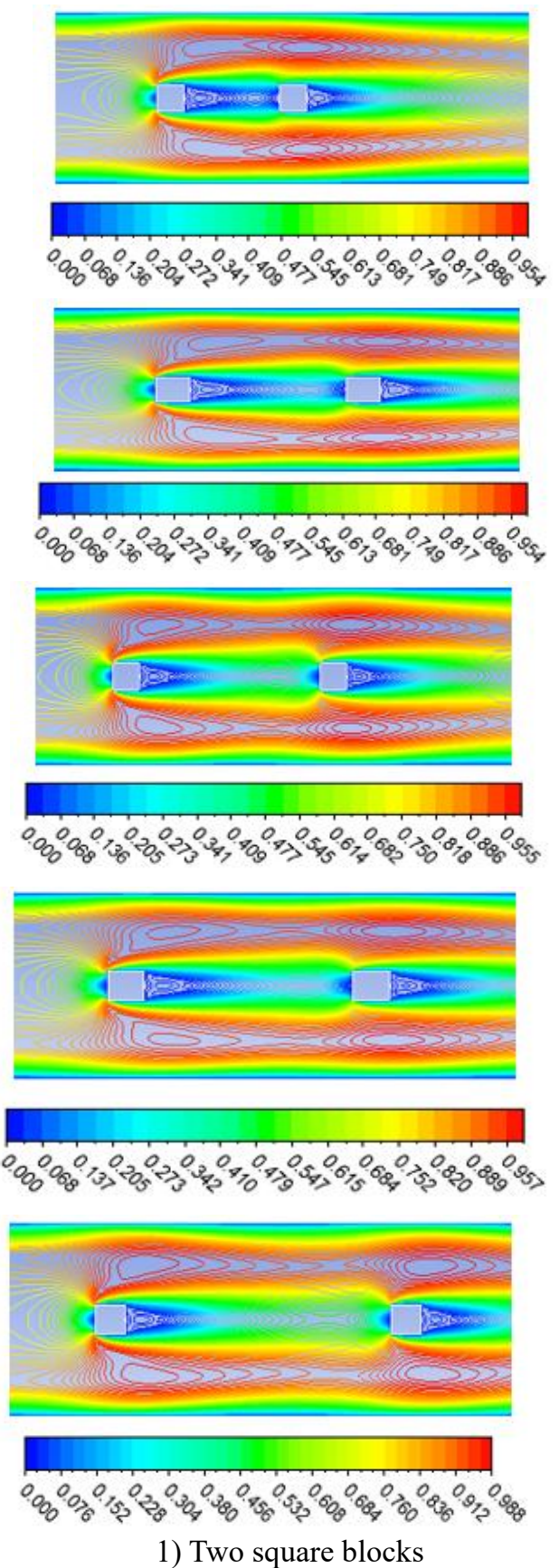

a)

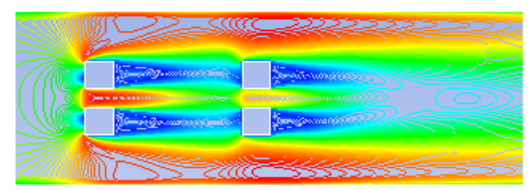

b)

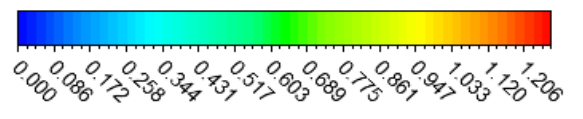

c)
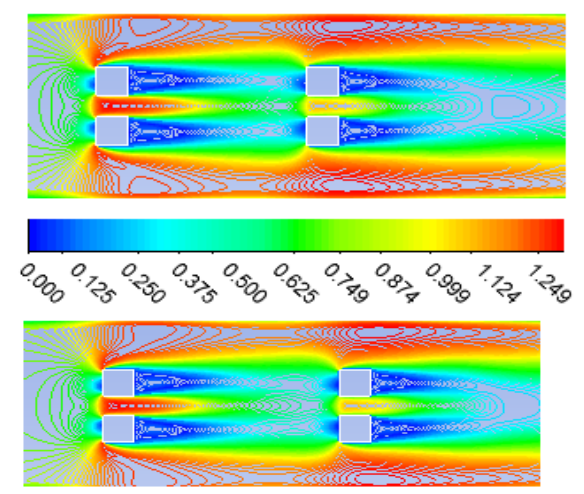

d)

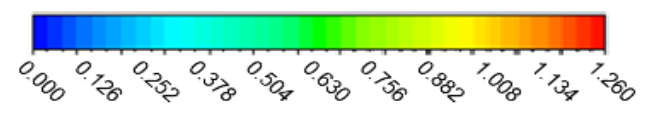

e)
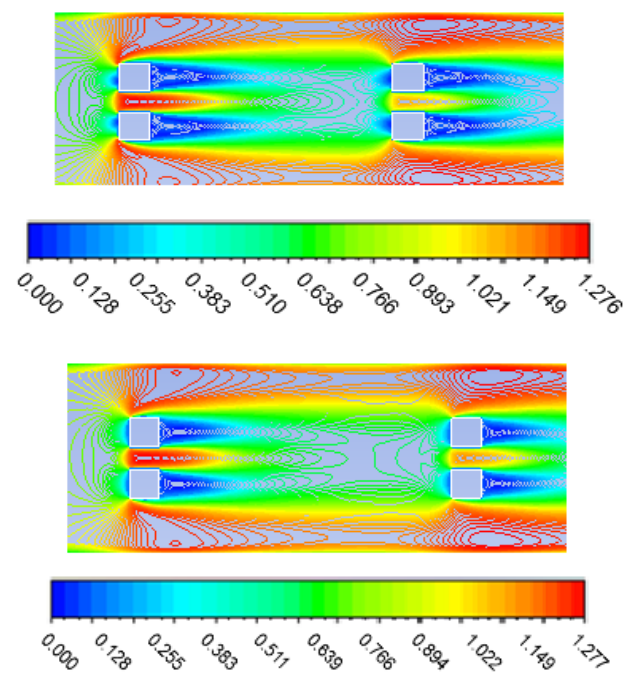

2) Four square blocks

Figure 6. Contour plots of the velocity magnitude for $\mathrm{R}_{\mathrm{e}}=10^{4}$, a) $G_{L} / d=5.5$, b) $G_{L} / d=6.665$, c) $G_{L} / d=7.75$, d) $G_{L} / d$ $=8.875$, e) $G_{L} / d=10$ : case 1 (Two square blocks), case 2 (Four square blocks for different $G_{L} / d$ and $G_{T}=0.029 \mathrm{~m}$ ) 

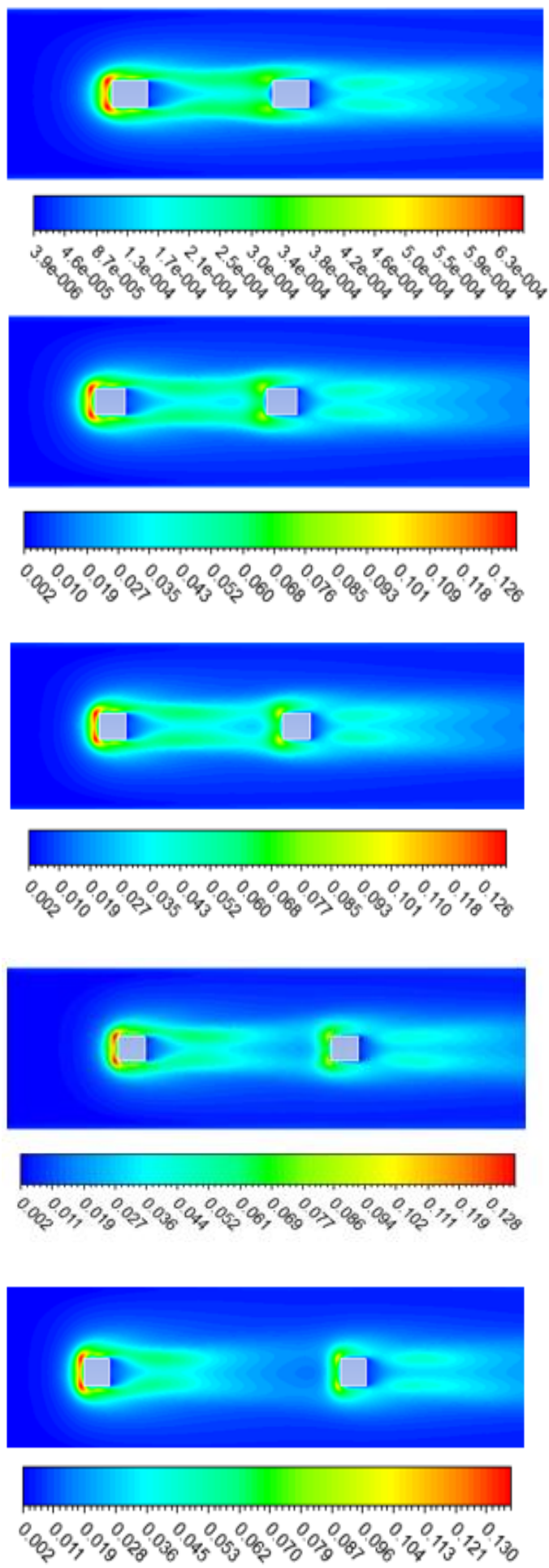

1) Two square blocks a)
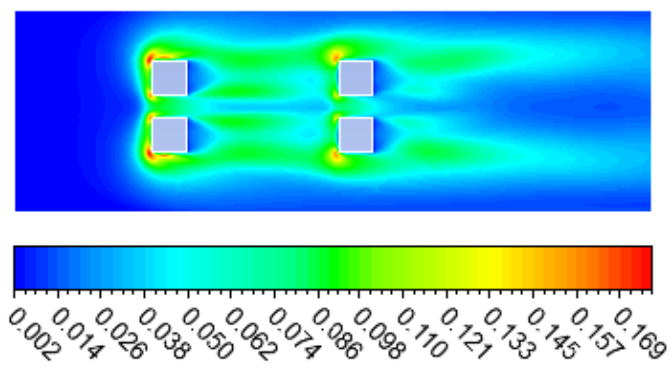

b)

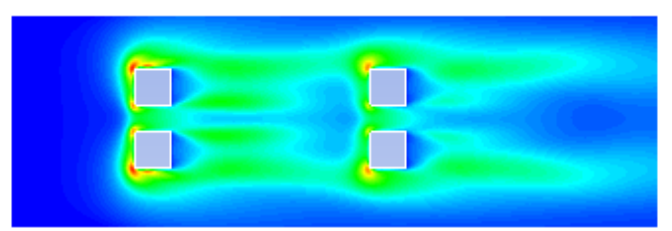

c)
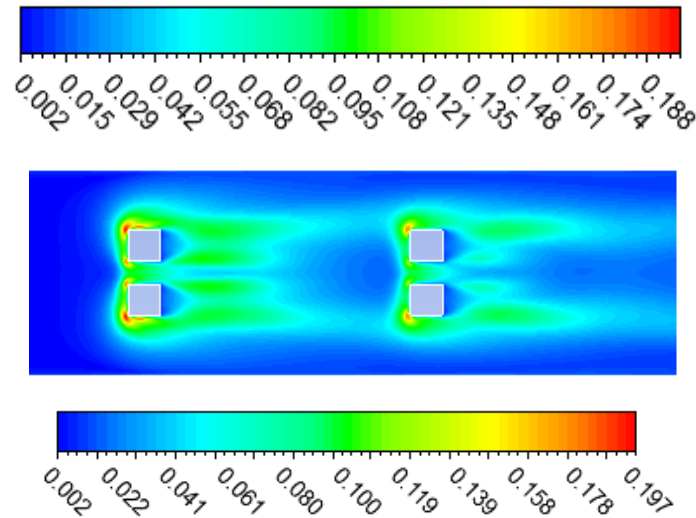

d)
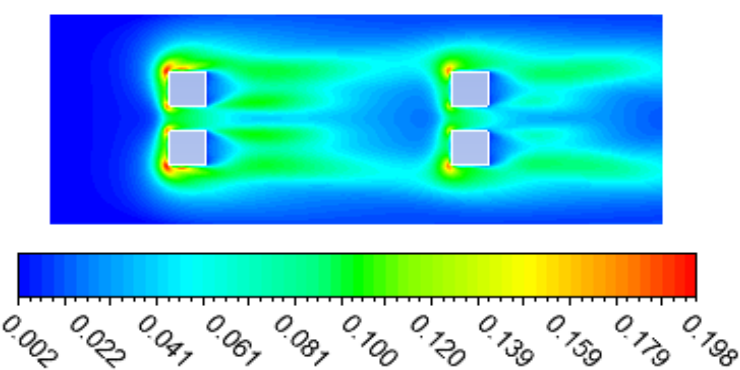

e)
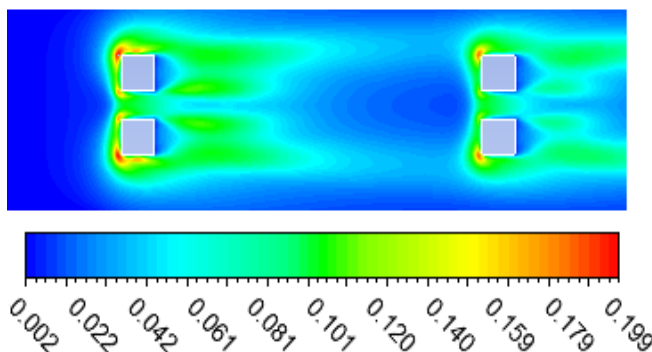

2) Four square blocks

Figure 7. Contour plots of the turbulent kinetic energy for $R_{e}=10^{4}$, a) $G_{L} / d=5.5$, b) $G_{L} / d=6.665$, c) $G_{L} / d=7.75$, d) $G_{L} / d=8.875$, (e) $G_{L} / d=10$ 
Results indicate that the size of the recirculation vortex behind the first square block becomes important and tends to elongate between the two blocks space when this space is increased. The velocity is highly affected when the blocks are in tandem arrangements. It can be noted that with the increase in the longitudinal spacing between the blocks, the velocity become important also the vortex formation in the upper and lower second block are very important for the case $G_{L}=10 d$ compared to other cases.

These results indicate that the obstacles resistance to the air flow for the case of $G_{L}=10 d$ is less which allows the air circulation between the blocks and the formation of circulating vortices. In Figure 6, the comparison between the contour plot of the magnitude velocity for the two blocks arranged in tandem way and the four blocks arranged side by side is also presented. Results shows that for the blocks arranged side by side, the downstream flow between the upper and lower blocks and the surrounding walls is more intensified compared to the tandem arrangement. This is due to the reduced flow passage and the increased velocity. This is clearly shown in Figure 7 (case 2) for the turbulent kinetic energy contours which become important near these regions. Figure 7 (case 1) show the corresponding contour plots of the turbulent kinetic energy $k$ for all cases of tandem arrangements $G_{L} / d=5.5,6.665,7.75,8.875$ and 10 . Results shows that the maximum value of the turbulent kinetic energy is shown in the upstream faces of the first square blocks, more precisely near the corners where the flow gradient is important. It is shown also that the contour plots of the kinetic energy increase at the upstream and the downstream blocks when increasing the space between the blocks. Moreover, for the tandem arrangements the contours of turbulent kinetic energy increase with increasing the longitudinal distance between the blocks. These turbulent kinetic contours show the role of the arranged blocks in flow disturbance which promote turbulence and more importantly for the side by side case as shown in Figure 7 (case 2). Thus, the flow disturbance consequently increases the heat transfer between the solid and adjacent fluid particles and between the fluid particles themselves.

\section{Local and average Nusselt number}

Figure 8a shows the local Nusselt number distributions $N u$ as a function of the channel length for the five cases with the blocks arranged in tandem. It is clear that the high value of the local Nusselt number is obtained at the inserted location of the upstream and downstream block, respectively. The effect of the spacing between the blocks on the heat transfer for the cases $G_{L}=8.875 \mathrm{~d}$ and $G_{L}=10 \mathrm{~d}$ becomes important. When $G_{L}$ increases, the heat transfer at the channel exit is increased. Moreover, the spacing between the blocks seems to have substantial effects on the local Nusselt number within the channel duct. The variation of the local Nusselt number along the channel length for the case of four square blocks and different values of $G_{T}\left(G_{L}=10 d\right.$, at $\left.R e=10^{4}\right)$ is illustrate in Figure $8 \mathrm{~b}$.

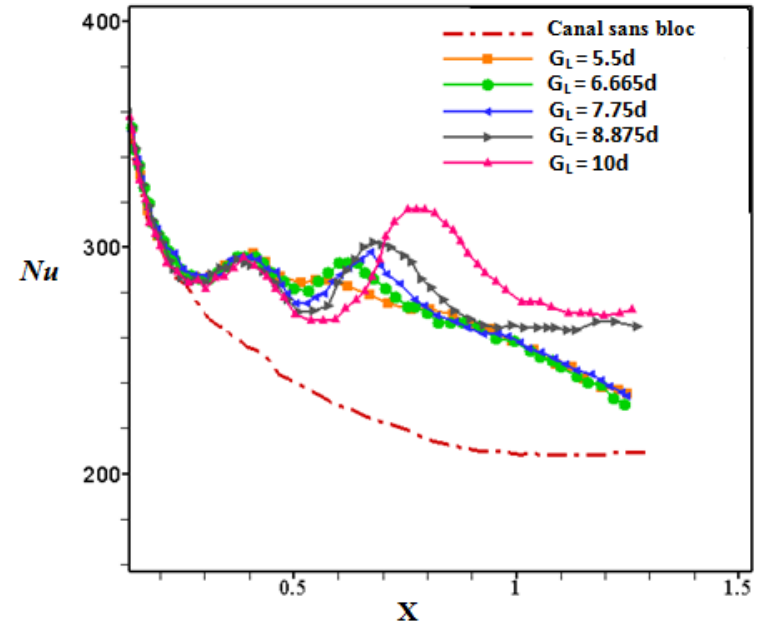

a) Two square blocks

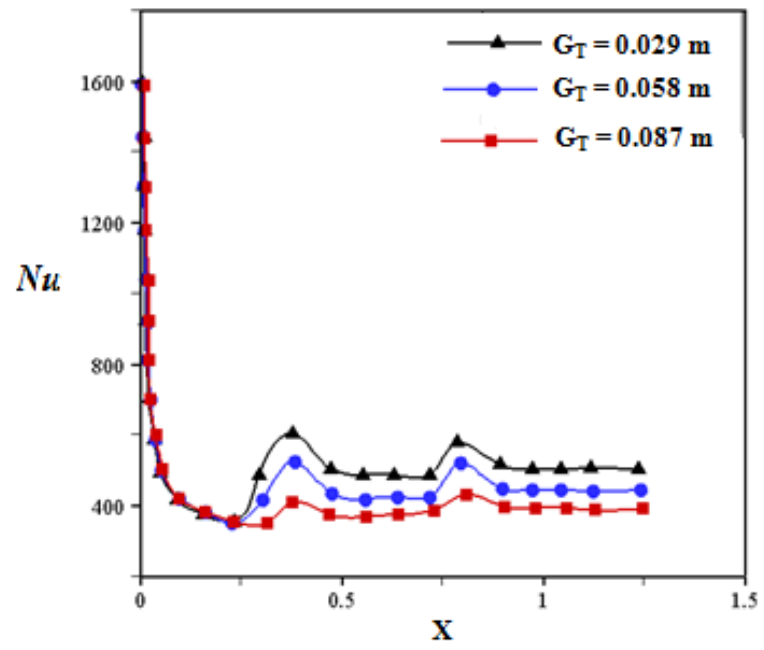

b) Four square blocks

Figure 8. Variation of the local Nusselt Number along the channel length for $R e=10^{4}$ a) two and, b) four square 
It can be noticed that $N_{u m}$ decreases along the axial distance of the channel and then become more significant at the position of the central blocks $\left(\mathrm{x}_{1}, \mathrm{x}_{2}\right)$ and varies slightly downstream the blocks. It can be noticed also that the highest values of $N_{u m}$ could be obtained for the lowest transverse spacing between the blocks $G_{T}=0.029$. Concluded that the inclusion of transverse spacing between the blocks improves the heat transfer rate compared to the smooth case (channel without blocks). Figure 9a shows the variation of the average Nusselt number $N u_{m}$ as function of Reynolds number for the square blocks of $d / H=0.152$ and for different longitudinal spacing between the blocks $G_{L}$. It is shown that increasing $R e$ leads to significant increase in Nusselt number. The variation is almost linear; Furthermore, $N_{u m}$ increases with increasing the longitudinal space between the blocks $G_{L}$.

In addition, the presence of the longitudinal spacing between the blocks leads to considerable enhancement on the average Nusselt number compared with the smooth channel case (without blocks) at $R e=5 \times 10^{4}$, the improvement is about $32 \%$. One notes that this is observed for the case of four blocks arranged side by side as shown in Figure 9b in which $N_{u m}$ number is increased with $R e$ number. However, the space $G_{T}$ has no significant effect on $N_{u m}$ compared with $G_{L}$.

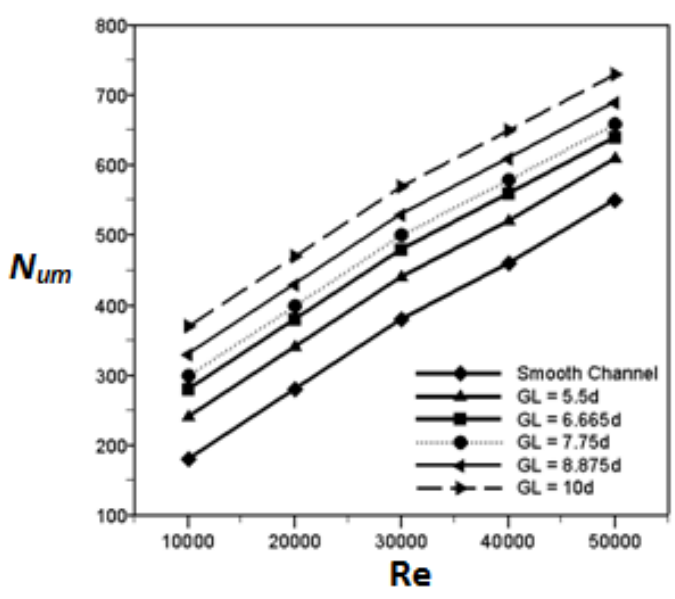

a) Two square blocks

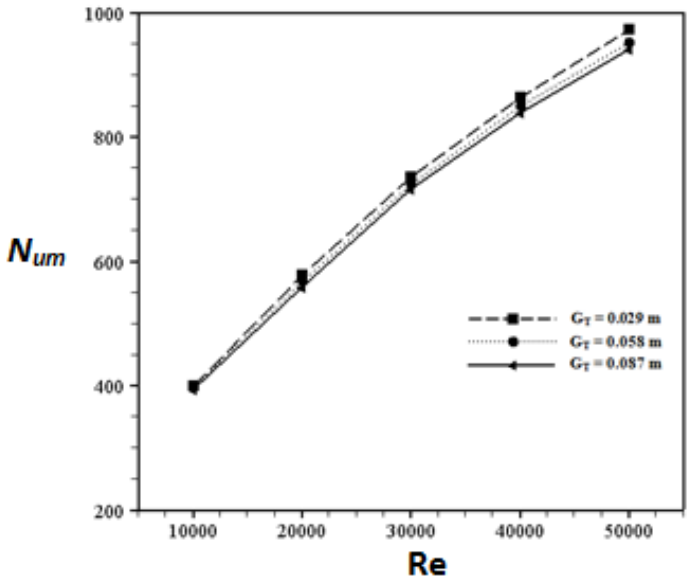

b) Four square blocks

Figure 9. Average Nusselt number versus Reynolds number for the case $d / H=0.152$, a) two and, b) four square

\section{Local and average skin friction factor}

It is well known that the inclusion of internal obstacle may improve the heat transfer characteristics; however, the presence of these obstacles induces an increase in the skin friction coefficient leading to higher pressure drop. The local skin friction coefficient distributions on the channel walls are presented in Figure 10a for the five studied tandem arrangements of the square blocks. The maximum local skin friction coefficient is obtained at the inserted position of the first block and decreases slightly between the two blocks whatever is the shape or the longitudinal spacing of the blocks.

This coefficient increases at the positions of the second block and remains a little constant in the exit of the channel. At $R_{e}=10^{4}$, when the flow is steady, the effect of the presence of the longitudinal spacing between the blocks is more important, $C_{f}$ increases immediately with increases $G_{L}$. For this, the case of $G_{L}=10 \mathrm{~d}$ becomes more important compared with smooth channel (this augmentation is about $50 \%$ ).

Figure $10 \mathrm{~b}$ shows the variations of the skin friction coefficient along the channel length for the case of four square blocks placed in side by side arrangement. The transverse spacing between the blocks $G_{T}$ considered varies from $0.029 \mathrm{~m}, 0.058 \mathrm{~m}$ to $0.087 \mathrm{~m}$. It can be noted that the skin friction coefficient $C_{f}$ decreases along the upstream location of the two blocks and then suddenly increases to maximum values at the inserted positions of the blocks. Furthermore, the maximum values could be obtained for the transverse spacing of $G_{L}=0.029 \mathrm{~m}$. 


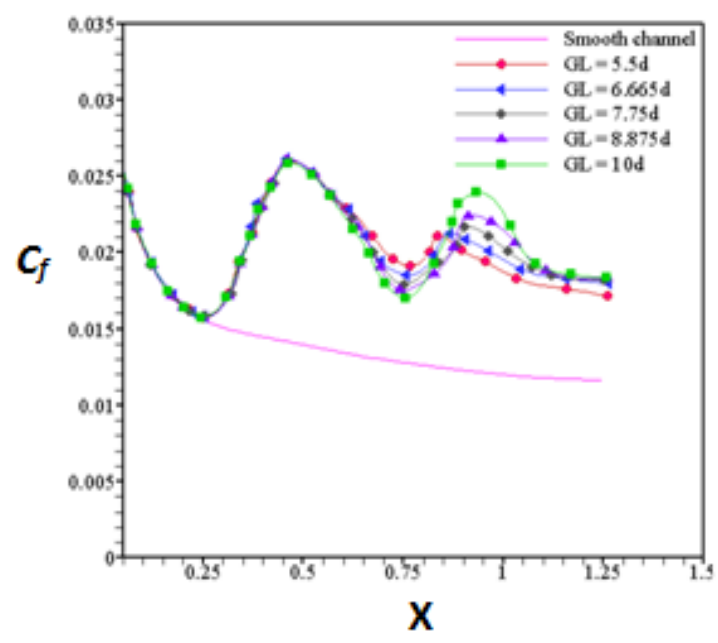

a) Two square blocks

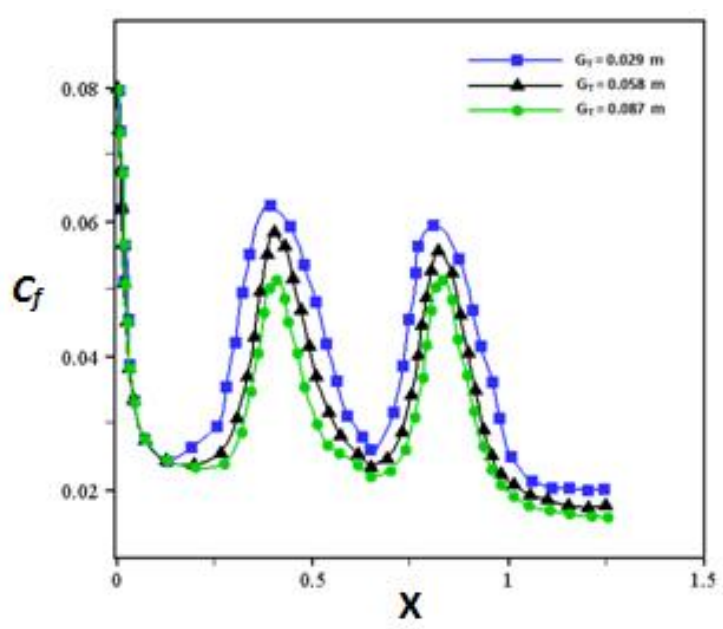

b) Four square blocks

Figure 10. Variation of the local skin friction for different values of $G_{L}$ (case a) and $G_{T}$ (case b) for $\operatorname{Re}=10^{4}$, a) two and, b) four square

The influence of $R e$ on average skin friction for the mounted square blocks of $d / H=0.152$ was also studied. Figures 11a and 11b shows the results of the average local skin friction versus Re number for cases of two blocks in tandem arrangement and four blocks in side by side arrangement, respectively. For all configurations, when increasing Reynolds number, the friction loss becomes higher. Furthermore, the friction factor is more important when increasing the spacing $G_{L}=10 d$ and becomes lower when the space decreases $\left(G_{L}=5.5 d\right)$. However, when the transverse space $G_{T}$ between the side by side arranged square blocks increases as shown in Figure 11b, the skin friction increases. In addition, in the case with the square blocks placed in tandem arrangement, results show that the skin friction coefficient distributions are much greater compared to the case of side by side arrangement, this is due to the increased contact surface between the fluid and the square blocks. Indeed, the average skin friction coefficients on the blocks decrease with larger transverse spacing distances of the blocks, because more fluid flow a strong velocity gradient between the blocks for higher $G_{T} / d$.

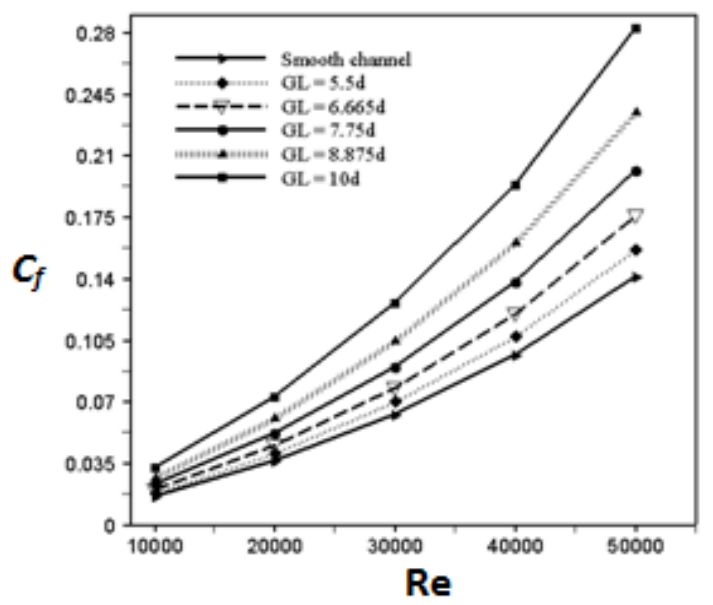

a) Two square blocks

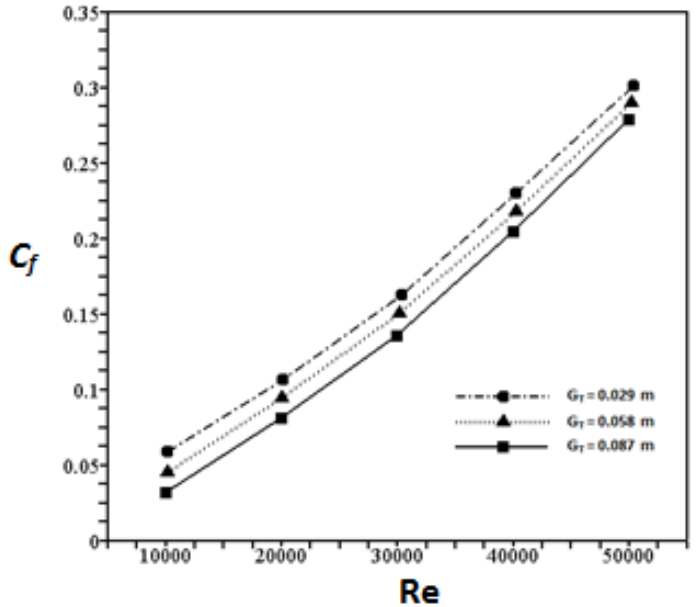

b) Four square blocks

Figure 11. Average skin friction versus Reynolds number for several spacing $G_{L}$ (case a) and $G_{T}$ (case b) for $R e=10^{4}$ 


\section{CONCLUSION}

The present numerical study is carried out to investigate the turbulent convective flow in straight channel with internal square blocks. Two cases are considered, first case with two square blocks in tandem arrangement and the second with four square blocks in side by side arrangement. The focus is investigated the effect of the space between these blocks on the flow and heat transfer rate. The following conclusions can be drawn from the obtained results:

- As the longitudinal spacing $G_{L}$ is increased, both the heat transfer rate and the skin friction coefficient are increased.

- As the transversal spacing $G_{T}$ is decreased, both the heat transfer rate and the skin friction coefficient are increased.

- The heat transfer rate for the case of varied transversal spacing $G_{T}$ for four arranged side by side square blocks is higher than the case of two arranged blocks.

- A good comparison is obtained between the present numerical predictions and those of Alvarez et al. [28].

\section{NOMENCLATURE}

$C_{f} \quad$ Skin friction coefficient

$C_{D} \quad$ Drag coefficient

d Dimensions of the block, $m$

$f \quad$ Friction factor for the channel

$f_{0} \quad$ Friction factor for the channel without square block

$G_{L} \quad$ Transverse spacing between the square blocks, $\mathrm{m}$

$G_{T} \quad$ Longitudinal spacing between the square blocks, $\mathrm{m}$

$\mathrm{H} \quad$ Channel height, $\mathrm{m}$

$h_{x} \quad$ Local heat transfer coefficient, $\mathrm{W} / \mathrm{m}^{2} . \mathrm{K}$

$\lambda_{f} \quad$ Thermal conductivity, W/m.K

L Length of the channel duct, $\mathrm{m}$

$\mathrm{L}_{1} \quad$ Distance between inlet and first square block, $\mathrm{m}$

$\mathrm{L}_{2}$ Longitudinal spacing between the square blocks (=10d), $\mathrm{m}$

$C_{\mu} \quad$ Empirical constant for the standard $k-\varepsilon$ model

$C_{1}, C_{2}$ Constants for the standard $k-\varepsilon$ model

$\sigma_{k}, \sigma_{\varepsilon}$ Turbulent Prandtl numbers of $k$ and $\varepsilon$

$\mathrm{Nu} \quad$ Local Nusselt number

$\mathrm{Nu} u_{0} \quad$ Local Nusselt number without square block

$\mathrm{Nu} u_{m} \quad$ Average Nusselt number

$\mathrm{P}$ Pressure, $\mathrm{Pa}$

$P_{r} \quad$ Prandtl number, $v / \alpha$

$R_{e} \quad$ Reynolds number, $\rho D_{H} U_{0} / \mu$

$\mathrm{T}_{\mathrm{b}} \quad$ Fluid bulk temperature, $\mathrm{K}$

$\mathrm{T}_{\mathrm{w}} \quad$ Channel wall temperature, $\mathrm{K}$

$\mathrm{T}_{\text {int }} \quad$ Inlet fluid temperature, $\mathrm{K}$

$\mathrm{U}_{\text {int }}$ Inlet velocity, $\mathrm{ms}^{-1}$

$u, v \quad$ Fluid velocity in the $\mathrm{x}$-and $\mathrm{y}$-direction, $\mathrm{ms}^{-1}$

Greek symbols

$\mu \quad$ Dynamics viscosity of the fluid, Pa.s

$v \quad$ Kinematic viscosity of the fluid, $\mathrm{m}^{2} / \mathrm{s}$

$\rho \quad$ Density of the air, $\mathrm{kg} \mathrm{m}^{-3}$

$\alpha \quad$ Thermal diffusivity, $\mathrm{m}^{2} \mathrm{~s}$

Subscript and Superscripts

w Wall

f Fluid

in, Inlet of the test section 
out Outlet of the test section

$\mathrm{t}$ Turbulent

e Effective

\section{REFERENCES}

[1] Incropera F.P. Convection heat transfer in electronic equipment cooling. Journal of heat transfer, vol. 110, 1988, p. 1097-1111. https://doi.org/10.1115/1.3250613.

[2] Peterson G.P, Ortega A. Thermal control of electronic equipment and devices. Advances in heat transfer, vol .20, 1990, p.181-314. https://doi.org/10.1016/S0065-2717(08)7002.

[3] Young T.J, Vafai, K. Convective cooling of a heated obstacle in a channel. International journal of heat and mass transfer, vol. 41, 1998, p. 3131-3148. https://doi.org/10.1016/S0017-9310(97)00323-2.

[4] Sheikholeslami M, Haq Rizwan-ul, Shafee A, Li Z, Elaraki Y.G, Tlili I. Heat transfer simulation of heat storage unit with nanoparticles and fins through a heat exchanger. International Journal of Heat and Mass Transfer, vol.135, 2019, p.470-478. https://doi.org/10.1016/j.ijheatmasstransfer.2019.02.003.

[5] Wu H.W, Perng S.W. Turbulent flow and heat transfer enhancement of mixed convection over heated blocks in a channel. International Journal of numerical methods for heat and fluid flow, vol.15, 2005, p.205-225. https://doi.org/10.1108/09615530510578456.

[6] Peng S.W, Wu H.W. Numerical investigation of mixed convective heat transfer for unsteady turbulent flow over heated blocks in a horizontal channel. International journal of thermal sciences, vol. 47, 2008, p.620-632. https://doi.org/10.1016/j.ijthermalsci.2007.04.003.

[7] Bouttout A, Benissaad S, Bessaïh R. Numerical study of forced convection in a horizontal channel with heated blocks due to oscillation of incoming flow. Numerical heat transfer, vol. 65, 2014, p.584-600. https://doi.org/10.1080/10407782.2013.836013.

[8] Yemenici, O., Firatoglu, Z.A. Tansitional boundary layer flow and heat transfer over blocked surfaces with influence of free stream velocity and block height. Heat and mass transfer, vol.49, 2013, p.1637-1646. DOI: $10.1007 / \mathrm{s} 00231-013-1208$.

[9] Nakagawa S, Senda M, Hiraide A, Kikkawa S. Heat transfer characteristics in a channel flow with a rectangular cylinder. JSME International journal series B fluids and thermal engineering, vol.42, 1999, p.188-196. https://doi.org/10.1016/j.ijthermalsci.2016.01.006.

[10] Kim D.H, Yang K.S, Senda M. Large-eddy simulation of turbulent flow past a square cylinder confined in a channel. Computers and Fluids, vol.33, 2004, p. 81-96. https://doi.org/10.1016/S0045-7930(03)00040-9.

[11] Parthasarathy R.K., Mahadevan S, Marimuthu U. Numerical investigation of forced convection conjugate heat transfer from square cylinders placed in a confined channel covered by solid wall. Heat Transfer-Asian Research, vol.46, 2015, p. 91-110. https://doi.org/10.1002/htj.21200.

[12] Valencia A, Cid M. Turbulent unsteady flow and heat transfer in channels with periodically mounted square bars. International journal of heat and mass transfer, vol.45, 2002, p.1661-1673. https://doi.org/10.1016/S0017-9310(01)00267-8.

[13] Valencia A. Heat transfer enhancement in a channel with a built-in square cylinder. International communications in heat and mass transfer, vol. 22, 1995, p. 47-58. https://doi.org/10.1016/07351933(94)00051-L.

[14] Frank R, Rodi W. Calculation of vortex shedding past a square cylinder with various turbulence models, turbulent shear flows, vol.8,1993, p.189-204. https://doi.org/10.1016/0142-727X(96)00033-1

[15] Kumar, A., Dhiman, A.K., Bharti, R.P. Power-law flow and heat transfer over an inclined square bluff body: effect of blockage ratio. Heat transfer-Asian Research, vol.43, 2014, p. 167-196. https://doi.org/10.1002/htj.21071.

[16] Bouchenafa R, Saim R, Abboudi S. Numerical study of forced convection in a turbulent heat sink made of several rows of blocks of square from. Heat and mass transfer, vol.51, 2015, p. 1301-1311. doi: 10.1007/s00231015-1496-4

[17] Barman A, Kumar Dash S. Effect of obstacle positions for turbulent forced convection heat transfer and fluid flow over a double forward facing step, International Journal of Thermal Sciences, vol.134, 2018, p.116-128. https://doi.org/10.1016/j.ijthermalsci.2018.08.009

[18] Zhang, W., Chen, X., Yang, H., Liang, H., Wei, Y. Forced convection for flow across two tandem cylinders with rounded corners in a channel, International Journal of Heat and Mass Transfer, vol.130, 2019, p. 1053-1069. DOI: 10.1016/j.ijheatmasstransfer.2018.10.125

[19] Zhan W, Yang H, Dou H, Zhu Zuchao. Forced convection of flow past two tandem rectangular cylinders in a channel. Numerical Heat Transfer. A-Appl, vol. 72, 2017, p. 89-106. 
https://doi.org/10.1080/10407782.2017.1353384

[20] M Sheikholeslam, M Jafaryar, Ahmad Shafee, Zhixiong Li, Rizwan-ul Hag. Heat transfer of nanoparticles employing innovative turbulator considering entropy generation, International Journal of Heat and Mass Transfer. Vol.136, 2019, p. 1233-1240.

https://doi.org/10.1016/j.ijheatmasstransfer.2019.03.091

[21] M. Sheikholeslam, M. Jafaryar, Mohammadali H, Ahmad Shafee, Zhixiong Li, Truong Khang Nguyen, Mohsen Bakouri. Heat transfer and turbulent simulation of nanomaterial due to compound turbulator including irreversibility analysis. International Journal of Heat and Mass Transfer, vol.137, 2019, p.1290-1300. https://doi.org/10.1016/j.ijheatmasstransfer.2019.04.030

[22] M. Sheikholeslami, Rizwan-ul Haq, Ahmad Shafee, Zhixiong Li. Heat transfer behavior of nanoparticle enhanced PCM solidification through an enclosure with V shaped fins. International Journal of Heat and Mass Transfer, vol.130, 2019, p. 1322-1342. https://doi.org/10.1016/j.ijheatmasstransfer.2018.11.020

[23] Launder B.E, Spalding D.B. The numerical computation of turbulent flows, Computer Methods in applied mechanics and engineering. Vol. 3, 1974, p. 269-289. https://doi.org/10.1016/0045-7825(74)90029-2

[24] Patankar S.V, Numerical heat transfer and fluid flow. CRC press, 1980.

[25] Saim R, Benzenine H, Oztop H.F, Al-Salem K.. Turbulent flow and heat transfer enhancement of forced convection over heated baffles in a channel. International Journal of Numerical Methods for Heat \& Fluid Flow, vol. 23, 2013, p.613-633. https://doi.org/10.1108/09615531311323773

[26] Nasiruddin M.H, Siddiqui K.. Heat Transfer Augmentation in a Heat Exchanger Tube using a Baffle, International journal of Heat and Fluid Flow, vol.28, 2007, p. 318-328. https://doi.org/10.1016/j.ijheatfluidflow.2006.03.020.

[27] Sripattanapipat P.S. Numerical analysis of laminar heat transfer in a channel with diamond-shaped baffles, International Communications in heat \& Mass Transfer, vol.36, 2009, p.32-38.

https://doi.org/10.1016/j.icheatmasstransfer.2008.09.008

[28] Alvarez J, Pap M, Valencia A. Turbulent Heat Transfer in a Channel with Bars in Tandem and in Side by Side Arrangement, International journal of numerical methods for heat and fluid flow, vol.10, 2000, p. 877-895. DOI:10.1108/09615530010359157

[29] Belhadj A, Bouchenafa R, Saim R. Numerical investigation of forced convection of nanofluid in microchannels heat sinks, Journal of thermal engineering, vol.5, 2018, p.2263-2273. https://doi.org/10.1016/j.ijthermalsci.2013.07.020 